\title{
Local Content Development to Sustain Rural Community Economic in Malay Cottage Industry
}

Norhayati Hussin, Nurul Syfa' Mohd Tokiran, Mohd Sazili Shahibi, Masitah Ahmad, Ezza Rafedziawati Kamal Rafedzi, Mazlina Pati Khan, Nurhidayah Hashim

To Link this Article: http://dx.doi.org/10.6007/IJARBSS/v10-i11/9069

DOI:10.6007/IJARBSS/v10-i11/9069

Received: 20 September 2020, Revised: 22 October 2020, Accepted: 14 November 2020

Published Online: 28 November 2020

In-Text Citation: (Hussin et al., 2020)

To Cite this Article: Hussin, N., Tokiran, N. S. M., Shahibi, M. S., Ahmad, M., Rafedzi, E. R. K., Khan, M. P., \& Hashim, N. (2020). Local Content Development to Sustain Rural Community Economic in Malay Cottage Industry. International Journal of Academic Research in Business and Social Sciences, 10(11), 1444-1452.

Copyright: (c) 2020 The Author(s)

Published by Human Resource Management Academic Research Society (www.hrmars.com)

This article is published under the Creative Commons Attribution (CC BY 4.0) license. Anyone may reproduce, distribute, translate and create derivative works of this article (for both commercial and non-commercial purposes), subject to full attribution to the original publication and authors. The full terms of this license may be seen at: http://creativecommons.org/licences/by/4.0/legalcode

Vol. 10, No. 11, 2020, Pg. 1444 - 1452

Full Terms \& Conditions of access and use can be found at http://hrmars.com/index.php/pages/detail/publication-ethics 


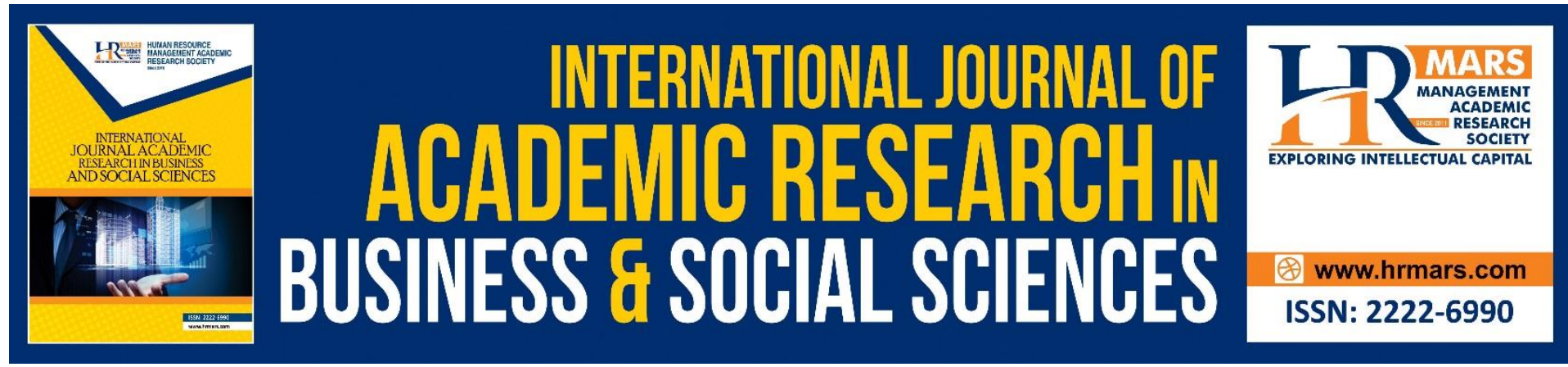

\title{
Local Content Development to Sustain Rural Community Economic in Malay Cottage Industry
}

\author{
Norhayati Hussin, Nurul Syfa' Mohd Tokiran, Mohd Sazili \\ Shahibi, Masitah Ahmad, Ezza Rafedziawati Kamal Rafedzi, \\ Mazlina Pati Khan, Nurhidayah Hashim
}

Faculty of Information Management, Universiti Teknologi MARA (UiTM) Selangor, Malaysia

\begin{abstract}
This paper address to formulate the conceptual model in enhances, manage and share the availability of the local content for Malay Cottage Industry. Furthermore, the limitation shows the gap in the existing literature that need to be closed by providing a complete insight into how to enhance the availability of local content among society in Malaysia. Therefore, there must be an initiative to enhance the availability of local content to the society, which will be focused on this research. The ethnography method will be applied through the semistructured interview to understand and to obtain in-depth knowledge of the culture as well as the current scenario of the rural community in the Malay Cottage Industry. The combination of data collection strategies allows researchers to triangulate data in getting conclusive evidence for the formulation of the comprehensive model for enhancing the availability of local content on cottage industry for the better quality life of the citizen, which reflect the national agenda of communications contents and infrastructure.
\end{abstract}

Keywords: Library and Information Management, Local Content Management, Rural Community, Cottage Industry

\section{Introduction}

A rural community who live in the rural area can use the natural resources, cultural and historical resources that can be a basis for economic development in Malaysia (Ellfrelstern, 2018). The industry that commonly participates by a rural community in a rural area is Malay Cottage Industry. This industry is small scale industry which has been handled by Malay people and will operate in the home. The number of products on the product is not in a mass quantity because this kind of entrepreneur has a few numbers of workers and cannot produce a large quantity of product. The entrepreneur who involved in this small scale industry will be called culture heritage entrepreneur. This kind of entrepreneur will produce a product related to local culture and represents it in the form of the product. Usually, the culture heritage entrepreneur will offer goods and services to the customer and product that has been offers are cultural content and less commercially.

Handicraft or craft product is one of the goods that have been offered by the culture heritage entrepreneur. There is various craft product that significance and unique and show the 
culture and heritage that has been preserved by local people offer by the cultural heritage entrepreneur. The creative touch from crafts designer has combined traditional, and contemporary form already elevates the Malaysia product internationally (Malaysia Craft, 2018). The combination design of modern and contemporary will attract tourist or local people from different state purchasing the craft product as a gift or souvenir to their family. Delicate hand-made of craft product by local people show the creativity of them to interpret based on the environment surround by local people. The most uniqueness of the craft product is related to the knowledge represented by local people. The skill and knowledge in producing the craft product have been passed generation by generation, and the local people still maintain the knowledge-producing the craft product.

Local knowledge also can be interpreted as local content. Based on UNESCO (2001), local content defined as an expression and communication of a community's locally generated, owned and adapted knowledge and experience that is relevant to the community's situation. Local content area not only covers by UNESCO but the understanding of the local content also used by the oil and gas industry. Oil and gas industry defined local content as the development of local skills, oil and gas technology transfer, and use of manpower and local manufacturing (Asamoah, 2010). The definition of the local content is slightly different with local content as defined by UNESCO. Even though the definition is slightly different, but the main point still relates to the local skill and knowledge of the local people based on local people's area or situation.

Therefore, there is a significant value to propose a comprehensive model to enhance the availability of local content to society. The adoption of local content in national legal frameworks has gained popularity worldwide, and the topic has become part of the policy debate regarding extractive sectors in many countries such as Norway (Heum, 2008), Nigeria (Heum, et al., 2003; Ovadia, 2014) and Brazil (Tordo \& Anouti, 2013). In Malaysia, however, has scarcely been discussed by the researcher and hardly been adopted that suits society. The model will base on society requirements encompassing every aspect of their local content.

\section{Problem Statement}

The development of local content is important--documenting, preserving, and disseminating of the national heritage of the country for sustainable national development. Local content on cottage industry is the expression and communication of knowledge and experience generated, owned and adapted and used in communities about the situation of a local community. The community with local knowledge can help the government to solve problems related to the environment, climate and others in their surrounding areas. Such information is critical to be kept and preserved to inherit to the younger generation. Local content on cottage industry is usually derived from the experience and ability of someone to interpret the surroundings in making a decision. Thus, this ability does not exist in every human being.

Most of the world content still inaccessible even to the local population, not mention the broader level (Bruegge et al., 2011). Usually, the knowledge and information that does not make easily accessible by other is local content. According to Ngulube (2002) and Wilder, et al. (2016), local content that does not record or preserved will be lost and remains inaccessible to others community's system. Wilder, et al. (2016) also state that local content has considered as the cornerstone that can guarantee the survival of economics of the 
developing country. The integrated of local content will assist the government in providing a sustainable solution for the country. Large amounts of related information are accessible, but users may find it difficult to sift through all the available information and find the relevant bits (OECD/ISOC/UNESCO, 2013). Hassan et al (2019) also state searching information is easier to do however the challenge is to filter the relevant information needed. If the community does not take the initiative from the local knowledge, they cannot assist the government in solving the problem related to the environment and climate-changing for sustainable development of the country. This is because local content provide good quality of information to the government. According to Azemi et al., (2017), the high quality of information that been produce can improve decision making process and become competitive advantages to the organization. It is very crucial to generating local content with the view to making the resources is available in traditional and new to assist the society and lead them to inclusive knowledge (Salawu, 2010).

\section{Literature Review}

Malay Cottage Industry is a small industry that been operated in the home by Malay people. The definition of a cottage industry by Investopedia (2019) is a small scale; decentralized manufacturing business often operated out of a home rather than a purpose-built facility. While Merriam Webster Dictionary (2019) defined the cottage industry as an industry whose labour force consists of the family unit or individual working at home with their equipment. This kind of industry will be operating in the area of the house with a short number of the employee. In Malaysia, Pahang, Terengganu and Kelantan are the area or location that known for its creation of the product and services at home. The buyer will get the product that is a unique, hand-made and good quality of the product when dealing with the cottage industry manufacturer. The most important is the product that has been made in this industry is onea-kind product because their product made from good quality of the raw material with a unique design based on the requirement from the customer.

Definitions of local content vary greatly across, and within, host countries. 'National content', 'Indigenous content', 'community content', 'shared value', 'in-country value', 'local participation' and 'industrial benefits' are some of the different terms used, while there is also the concept of 'supplier diversity'. Variations in definitions can be recognized, at least in part, by identifying the intended beneficiary, and assessing what specifically is being sought. Resource developers have to manage the variations in country-specific definitions of local content. Equally, governments and other stakeholders need to understand the differences when making comparisons between countries. There is the various kind definition of the local contents based on an understanding of the author or researcher in the social science field. The economist definition of local content is that it is the proportion of input which comes from the country itself; as opposed to those imported (Uzuegbu, 2012). The local's contents from the communities are relevant because they contain valuable information towards the national heritage of the country. Local content is an expression and communication of a community's locally generated, owned and adapted knowledge and experience that is relevant to the community's situation (UNESCO, 2001). Each country in the worlds has its uniqueness of the local contents depend on the country and their environment. This study will use the definition of local content suggested by UNESCO. UNESCO (2001) has defined "local content" as an expression and communication of a community's locally generated, owned and adapted knowledge and experience that is relevant to the community's situation. 


\section{Enhancing local content availability: a proposed model}

In this research, the proposed model adapt from the step of local content by UNESCO (2013), the creation of knowledge is the first stage in the development of local content to society. The sources of the knowledge come from society, especially old folk, that already have indigenous knowledge (IK). If indigenous knowledge (IK) is not recorded and preserved, the knowledge will be lost through the death of elders and traditional leaders (Owiny, Mehta \& Maretzki, 2014). That tacit knowledge will assist the researcher in managing and preserving the information for the future generation.

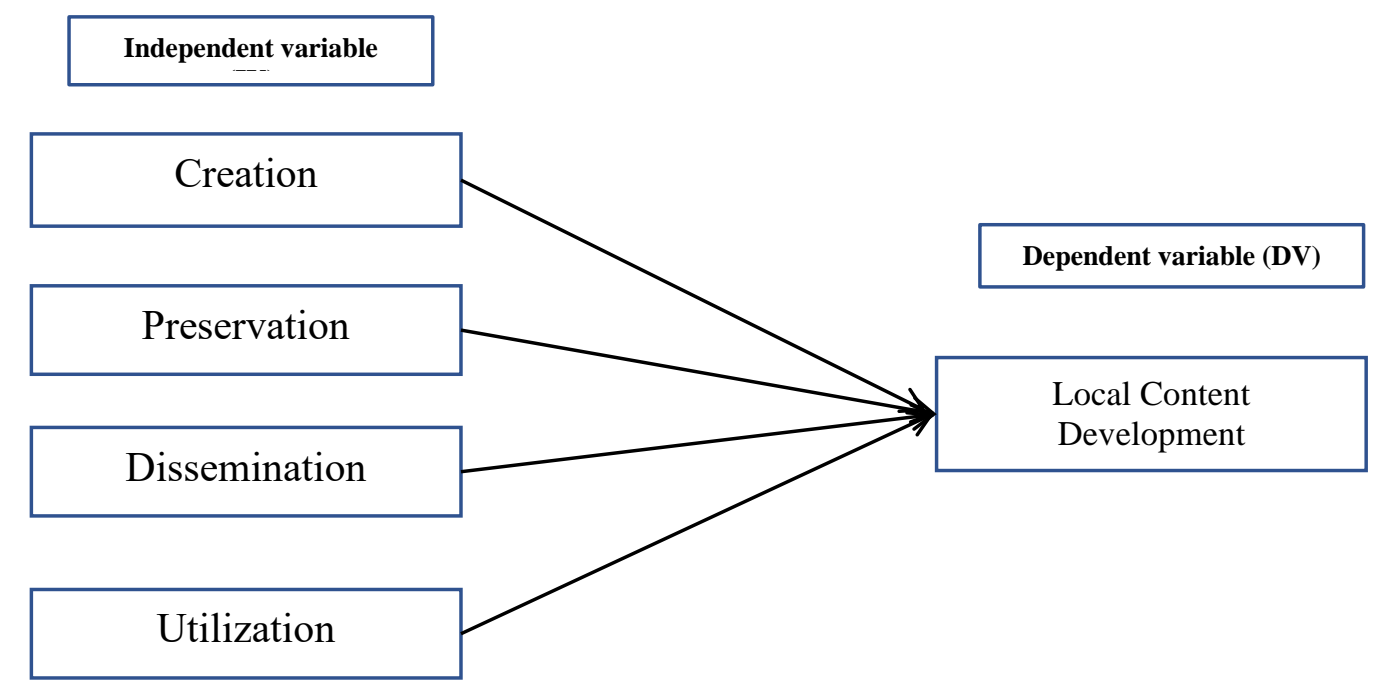

Figure 1: Proposed Conceptual Model

\section{Creation}

The creation of local content is talents exist in all communities around the world (UNESCO, 2011). There are many forms of knowledge and information has been created which are written document, video, audio, manuscript, wall and other material. The rapid and advancement of technology helped to increase the creation of local content, particularly by the non-professional content creator.

\section{Preservation}

Much of the content produced in the world is never recorded in a way that it can be shared or reproduced (UNESCO, 2011). It may seem because of the lack of awareness to preserve the knowledge and information related to the national heritage. There are various kinds of bodies that can help society to preserve indigenous knowledge. International Federal of Library Association and Institution (IFLA) respond to the need to preserve and disseminate indigenous knowledge properly. There are some recommendations made by IFLA which are:

The implementation programs to collect, preserve, disseminate IK and local/traditional knowledge resources.

a) Make available and promote information resources which support research and learning about IK and traditional knowledge, its importance and use in modern society

b) Publicize the value, contribution, and importance of IK and local traditional knowledge to both non-indigenous and indigenous peoples 
c) Involve elders and communities in the production of resources and teach children to understand and appreciate the traditional knowledge background and sense identity that is associated with IK systems

d) Urge governments to ensure the exemption from value-added taxes of books and other recording media on IK and local traditional knowledge

e) Encourage the recognition of principles of intellectual property to ensure the proper protection and use of IK products derived from it (IFLA, 2004).

In this study, the elements mention by IFLA will be a highlight. This research will assist the government and information and culture institution in retrieving their tacit knowledge and preserving that knowledge for an unborn generation. According to Isah et al. (2011), it also would increase the level of awareness, access and use of IK in the modern time especially with the advancement of Information and Communication Technology (ICT).

\section{Dissemination}

The local contents that already produce and preserves need to distribute in the ways that benefit to others (UNESCO, 2011). This stage will provide the society that rich with the information and knowledge related to the national heritage of their area. In the past, distribution of the indigenous knowledge limited only in printed material, but the advanced technology will rapidly spread the knowledge to the individual and society. The implementation of this study will assist the government and information, and cultural institutions in disseminating the knowledge to other communities for them know other culture and heritage of other society. That is important to create a knowledgeable society. There is various kind of media can be used to disseminate the knowledge related to indigenous knowledge. The right medium to deliver information and knowledge will help many people and the country.

\section{Utilization}

Disseminate of indigenous knowledge will help many institutions to be innovative in creating a product that may help the environment in the future. Local knowledge and content are of limited benefit if people do not access and use the information that has been created and recorded (UNESCO, 2011). The society or institution can utilize the knowledge itself for future benefit. For example, the information and knowledge from indigenous people will contribute to the development and improvement of the agriculture sector, herbs, culinary and other industry in the future. The knowledge on the new process in farming on the vegetable or other plants will assist agriculture sector. The new kind of herb may be discovered when getting that indigenous knowledge. The new ways of healing the disease may discover when they find new herbs. That is important to identify the new knowledge and can utilize new product and process.

\section{Methodology}

This research will adopt a qualitative approach by using ethnography methods to collect the data by exploring the current scenario of local content on the craft product in East Coast, Malaysia. Ethnography is a type of qualitative research that gathers observations, interviews and documentary data to produce detailed and comprehensive accounts of different social 
phenomena (Reeves et al., 2013). In this research, there are two phases in data collection, which is investigating the rural community with specific knowledge on the local cottage product. This kind of method will focus on the collective experience of community on the current scenario on the cultural heritage business, especially in the Malay Cottage Industry in Malaysia.

While the second phase, the researcher will interview 8-10 respondent, who has specific knowledge on local cottage product in a rural community. The researcher also will construct the interview question based on the important step to enhance the local content available based on the UNESCO point-of-view. The interview-based on the important step to enhance the local content according to UNESCO, which are creation, preservation, dissemination and utilization.

1) Creation - The creation of local content is talents exist in all communities around the world (UNESCO, 2011).

2) Preservation - The ways rural community preserve the local content within the rural area in their place

3) Dissemination - They ways on how rural community with indigenous knowledge on the production of cultural heritage product disseminate and share the knowledge within the community

4) Utilization - Disseminate of indigenous knowledge will help many institutions to be innovative in creating a product that may help the environment in the future. The society or institution can utilize the knowledge itself for future benefit.

The researcher will analyse the data by using the Atlas.ti based on the transcription from the recorded interview. The atlas.ti will analyze the complex and unorganized data from the transcription, and from the analysis, each of the elements will be given the themes. Based on the themes, the researcher can construct the model on local content development for a rural community in the preserve and share the local content of the community, especially at the East Coast of Malaysia.

\section{Conclusion}

In conclusion, this paper will formulate a conceptual model for the availability of local content to sustain the rural community economy, especially in the Malay Cottage Industry. This proposed conceptual framework will help the practitioner, government, industry as well as local people in preserving the local knowledge from lost. The model to enhance local content availability for sustainable development of rural community resulted from this research can be used by policymakers at state and federal level as a guideline for future decision making on the content delivery system used in the country. Local content, through proper approach and channel, can be served to the public at the right time and in an appropriate manner for their reference.

In facilitate Malaysia's shift towards a knowledge-based society, local content availability through this effort to provide access, and content, based on the comprehensive model which will be developed not only contribute towards national economy but it also a medium to preserving the local knowledge of local people in Malaysia. That is important preserving this 
kind of knowledge, especially to preserving the uniqueness of Malaysia, which has a variety of cultural heritage from a different race.

\section{Acknowledgement}

This article is financially supported by:

1. Faculty of Information Management, UiTM Selangor, Malaysia

2. Fundamental Research Grant Scheme (FRGS), Ministry of Education Malaysia. Reference Number: 600-IRMI/FRGS 5/3 (324/2019)

\section{References}

Asamoah, J. (2010). Local Content in the Oil and Gas Industry. Oil and Gas IQ website. https://www.oilandgasiq.com/strategy-management-and-information/articles/localcontent-in-the-oil-and-gas-industry

Azemi, N. A., Zaidi, H., \& Hussin, N. (2017). Information Quality in Organization for Better Decision-Making. International Journal of Academic Research in Business and Social Sciences, 7(12), 429-437.

http://hrmars.com/hrmars_papers/Information_Quality_in_Organization_for_Better_ Decision-Making.pdf

Bruegge, C., Ido, K., Reynolds, T., Serravallejo, C., Stryszowski, P., \& Van Der Berg, R. (2011). The Relationship between Local Content, Internet Development and Access Prices. OECD/UNESCO. https://www.oecd.org/internet/ieconomy/50305352.pdf

Ellfrelstern Anak Edirin. (2018). Opportunities and Challenges of Economic Development in Malaysia's Rural Areas. Trends in Undergraduate Research (2018) 1(1): h1-5

Hassan, Z., Hussin, N., Hashim, H., \& Tokiran, N. S. M. (2020). Information Seeking in Knowledge Society: Choose Right from Wrong. International Journal of Asian Social Science, 10(3), 151-158.

Heum, P. (2008). Local Content Development - Experiences from Oil and Gas Activities in Norway. SFN Report No. 25/03. Institute for Research in Economics and Business Administration, Bergen.

Heum, P., Quale, C., Karlsen, J., Kragha, M., \& Osahon, G. (2003). Enhancement of Local Content in the Upstream Oil and Gas Industry in Nigeria. SFN Report No. 25/30. Institute for Research in Economics and Business Administration, Bergen.

IFLA. (2014). IFLA Statement on Indigenous Traditional Knowledge. IFLA.org website. https://www.ifla.org/publications/ifla-statement-on-indigenous-traditionalknowledge

Investopedia. (2019). Cottage Industry. Retrieved May 2019, from, https://www.investopedia.com/terms/c/cottage-industry.asp

International Federation of Library Associations (2004). IFLA Statement on Indigenous and Traditional Knowledge, IFLA Newsletter, No. 42, June 2004.

Isah, A., Bashorun, M. T., \& Omopupa, K. T. (2012). Libraries and preservation of indigenous knowledge in developing countries: The Nigeria experience. In Library and Information Science in Developing Countries: Contemporary Issues (pp. 96-106). IGI Global.

https://www.researchgate.net/publication/287043467_Libraries_and_preservation_o

f_indigenous_knowledge_in_developing_countries_The_Nigeria_experience/citations

Malaysia Craft. (2018). Batik. Retrieved May 2019, from: http://malaysiancraft.com.my/

Merriem Webster Dictionary. (2019). Cottage Industry. Retrieved May 2019, from: https://www.merriam-webster.com/dictionary/cottage\%20industry 
Ngulube, P. (2002). Managing and Preserving Indigenous Knowledge in the Knowledge Management Era: Challenges and Opportunities for Information Professionals. Information Development, 18(2).

http://citeseerx.ist.psu.edu/viewdoc/download?doi=10.1.1.129.3196\&rep=rep1\&type $=p d f$

Owiny, S. A., Mehta, K., \& Maretzki, A. N. (2014). The use of social media technologies to create, preserve, and disseminate indigenous knowledge and skills to communities in East Africa. International Journal of Communication, 8 (14). http://ijoc.org/index.php/ijoc/article/view/1667/1067

Ovadia, J. (2012). The Dual Nature of Local Content in Angola's Oil and Gas Industry: Development vs. Elite Accumulation. Journal of Contemporary African Studies 30 (3) 123.

OECD/ISOC/UNESCO. (2013). The Relationship between Local Content, Internet Development and Access Prices. OECD Digital Economy Papers, No. 217, OECD Publishing. http://dx.doi.org/10.1787/5k4c1rq2bqvk-en

Salawu, B. A. (2010). Issues and challenges in the creation of institutional repositories with local content: critical reflections. Information, Society and Justice, 3(1). http://eprints.londonmet.ac.uk/91/1/InformationSocietyAndJustice_v3n1_p59-68.pdf Reeves, S., Peller, J., Goldman, J., \& Kitto, S. (2013). Ethnography in qualitative educational research: AMEE Guide No. 80. Medical Teacher, 35(8), e1365-e1379.

Tordo, S., \& Anouti, Y. (2013). Local content in the oil and gas sector: Case studies. The World Bank, Washington, DC.

UNESCO (2001). Introduction to UNESCO - United Nations Educational, Scientific and Cultural Organization. http://olympiads.win.tue.nl/ioi/misc/unesco.html

Uzuegbu, C. P. (2012). The role of Universities Library in enhancing local content availability in the Nigerian Community. Library Philosophy and Practice (e-journal). 733. https://digitalcommons.unl.edu/libphilprac/733/

Wilder, B. T., O'Meara, C., Monti, L., and Nabhan, G.P. (2016). The Importance of Indigenous Knowledge in Curbing the Loss of Language and Biodiversity, BioScience,66(6), 1 June, Pages 499-509, https://doi.org/10.1093/biosci/biw026 